\title{
DINÂMICA DO USO DA TERRA E DEGRADAÇÃO DO SOLO NA BACIA DO RIO GUABIROBA - GUARAPUAVA/PR ${ }^{1}$
}

\author{
Land use dinamics and soil degradation In \\ the Guabiroba catchment - Guarapuava/PR
}

\author{
Edivaldo Lopes THOMAZ²
}

\section{RESUMO}

O presente estudo avaliou a dinâmica do uso da terra e seus efeitos nas características físicas e na degradação do solo em Guarapuava/PR. Para isso, foi realizado preliminarmente o mapeamento da paisagem da bacia do Rio Guabiroba. Posteriormente foram selecionados os usos da terra mais freqüentes no âmbito da bacia. Nesses usos foram avaliadas algumas características biofísicas como dinâmica do uso da terra em agricultura de subsistência, serrapilheira estocada, resistência do solo, densidade aparente, porosidade total e infiltração de água no solo. O uso da terra na área de estudo apresenta um padrão em forma de mosaico (limites abruptos) em decorrência da diversidade de usos, bem como pelos compartimentos geomorfopedológicos bem definidos. Diante disso, verificou-se ampla variabilidade na dinâmica do uso da terra e das condições físico-hídricas do solo e, por conseguinte, distintos efeitos sobre a degradação do solo.

\section{Palavras-chave:}

Uso da terra; mudança físico-hídrica; degradação do solo.

\begin{abstract}
This study aims at assessing the land use dynamics as well as its effects in physical soil characteristics and on the soil degradation in Guarapuava/PR. First of all, the landscape mapping (land unit) of Guabiroba catchment was prepared. After that, the main land use in the study area was chosen. Next, it was sought to evaluate some attributes such as land use dynamics in subsistence agriculture, litter budget over the soil, soil resistance, bulk density, total porosity and water infiltration into the soil in each land unit. Due to land use diversity and well-defined landforms, the catchment area showed a mosaic pattern with abrupt boundary. In addiction to this, a wide variability of soil use and physical-hydric behavior was observed. As a result, diverse effects on soil degradation were found.
\end{abstract}

Key words:

Land use; physical-hydric changes; landscape degradation.

1 Este ensaio é parte da tese de doutorado Processos hidrogeomorfológicos e o uso da terra em ambiente subtropical - Guarapuava/ $P R$, defendida junto ao programa de Pós-Graduação em Geografia Física da Faculdade de Filosofia, Letras e Ciências Humanas, Universidade de São Paulo.

2 Professor Adjunto, Departamento de Geografia. Bolsista do CNPq durante a pesquisa. Universidade Estadual do Centro-Oeste do Paraná - UNICENTRO, Rua Simeão Camargo Varela de Sá, 3 - Cx. Postal 3010 - Centro Politécnico. Tel./fax: (042) 3629 - 8117, CEP 85040-430 - Guarapuava/PR. E-mail: ethomaz@brturbo.com.br. Agradeço a colaboração do agricultor Joel de Araújo Silvério. 
THOMAZ, E. L. Dinâmica do uso da terra e degradação do solo na bacia do Rio Guabiroba - Guarapuava/PR

\section{INTRODUÇÃO}

As paisagens são sistemas dinâmicos da superfície terrestre com estoque e transferência de matéria e energia. Portanto, ocorre processo de crescimento, decaimento, fluxo e transformação de matéria e energia dentro do sistema. (PHILLIPS, 1999)

Essa dinâmica ocorre sobre os diversos padrões espaciais dos sistemas da superfície da Terra (paisagens). As paisagens são padrões de rochas, relevos, solos e ecossistemas, padrões estes que são mantidos por processos naturais, sendo elas também expressões da história natural, incluindo impacto e manejo humano. (THOMAS; SIMPSON, 2001, p. 81)

$\mathrm{O}$ impacto do uso da terra sobre os sistemas naturais foi inserido gradativamente na Geografia Física, e com maior rapidez a partir de 1960. O homem (sociedade) foi reconhecido como agente de desflorestamento, denudação, desertificação, alteração climática e hidrológica. Afinal, o sistema ambiental teve seu fluxo de energia e matéria modificado e, portanto, os processos geomórficos, os limiares e a resiliência passaram a ter outros padrões, além dos padrões até então estudados. (GREGORY, 1992)

Por exemplo, o uso do solo para fins agrícolas modifica a bioestrutura do solo. Primavesi (1999) destaca que a mudança na bioestrutura do solo afeta a infiltração da água do solo. Assim, enquanto um solo sob floresta apresentou densidade de $1,07 \mathrm{~g} / \mathrm{cm}^{3} \mathrm{e}$ capacidade de infiltração de $148,1 \mathrm{~mm} / \mathrm{h}$, um solo após 14 anos de cultivo registrou densidade de 1,55 $\mathrm{g} / \mathrm{cm}^{3}$ e capacidade de infiltração de água de apenas $6,6 \mathrm{~mm} / \mathrm{h}$. A taxa de infiltração básica em ambos os solos foi obtida após 9 horas de ensaio.

As práticas agrícolas influenciam também na rugosidade superficial e, por conseguinte, tem papel fundamental na infiltração, no escoamento e na mobilização de solo. CASSOL et al. (1999) verificaram variação na rugosidade superficial para pastagens nativas (Rio Grande do Sul) de acordo com o manejo. Os valores foram os seguintes: testemunha: 0,5 $\mathrm{mm}$; plantio direto: $1,6 \mathrm{~mm}$; convencional: $1,1 \mathrm{~mm}$; subsolagem: $1,8 \mathrm{~mm}$; e gradagem: $0,7 \mathrm{~mm}$. Além disso, constataram correlação significativa $(85 \%)$ entre o aumento da rugosidade superficial e a taxa de infiltração.

A partir desses exemplos, verifica-se que as atividades agropecuárias são importantes fatores de controle na dinâmica da paisagem. Esses controles têm efeito sobre a circulação da água, na bioestrutura do solo, no adicionamento de resíduos/serrapilheira, no ciclo de sedimento e nutriente, entre outros efeitos.

O uso do geoprocessamento tem sido amplamente empregado nas últimas décadas nos estudos de ecologia da paisagem. As unidades de paisagens são obtidas por meio do cruzamento de mapas temáticos que representam as características do meio biofísico (uso da terra, formas de relevo, declividade, solo etc). Contudo, nesses estudos a observação sistemática em campo, mensurações e monitoramento de processos, variabilidade têmporo-espacial dos processos e manejo da terra, entre outros elementos, são às vezes negligenciados. Por conseqüência, há prejuízo analítico, explicativo e na predição acerca da dinâmica da paisagem. (THOMAZ, 2005a)

Corroborando com essa afirmação, Sotchava (1978) destaca que o mapeamento da paisagem deve aliar estudos experimentais, observações visuais e elaboração de modelos, com objetivo de verificar as características das unidades de paisagens acerca de suas homogeneidades e diferenciações.

Desse modo, o presente estudo objetiva enfocar a dinâmica da paisagem modificada pela ação humana em relação ao uso da terra e práticas agropecuárias, verificar os efeitos em algumas características físicas superficiais do solo (resistência, densidade aparente, porosidade total e infiltração) e analisar as implicações do uso da terra na degradação do meio biofísico. Tem por objetivo, ainda, demonstrar a aplicação de mensurações e observações sistemáticas simples, entretanto fundamentais nos estudos geomorfológicos, assim como no entendimento da dinâmica da paisagem.

\section{ÁREA DE ESTUdO}

O estudo foi realizado em Guarapuava, estado do Paraná (Figura 1). Em relação ao quadro natural, regionalmente a área se insere nos domínios morfoclimáticos dos planaltos sul-brasileiros com araucárias (AB'SABER, 1970) e na Subzona Ombrotérmica Planaltina com inverno acentuado e verão moderado (LEITE, 1995). A respeito dos aspectos litomorfológicos, a área em estudo faz parte do contexto da morfoestrutura intracratônica da bacia sedimentar do Paraná, táxon pertencente à morfoescultura do Terceiro Planalto do Paraná. (ROSS, 1992) 
FIGURA 1 - LOCALIZAÇÃO DA ÁREA DE ESTUDO

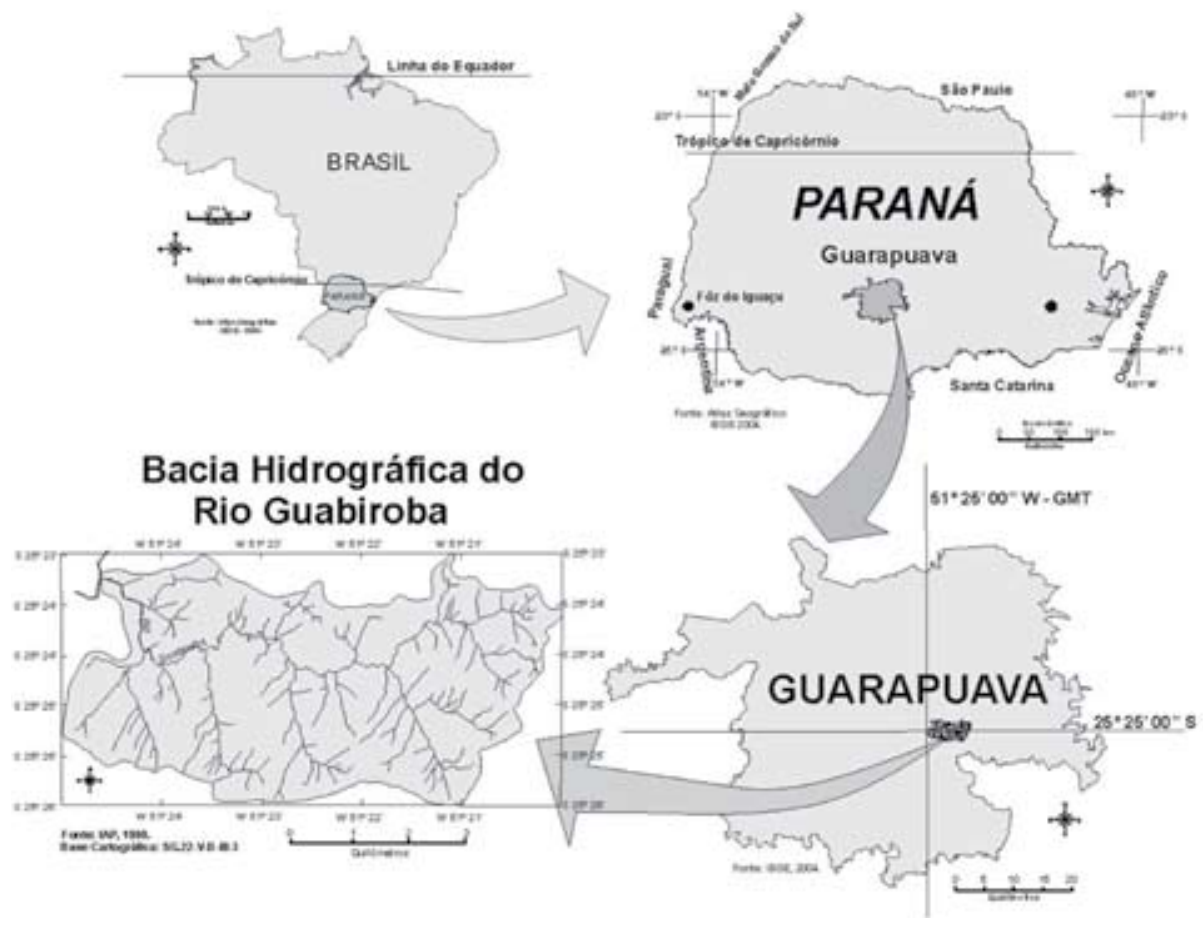

FONTE: Organizado por BERTOTTI, L. G.; THOMAZ, E. L. (2006).

O Terceiro Planalto Paranaense apresenta-se como região levemente ondulada, com chapadas e vertentes pouco inclinadas, sendo freqüente nesse planalto a presença de "mesas". A escultura da topografia dessa região está estritamente subordinada aos níveis das rochas eruptivas. As camadas de basalto deram lugar a plataformas estruturais que regulam a progressão da erosão. Dessa forma, a estrutura geológica desempenha papel importante sobre a ação erosiva dos leitos fluviais. As variações litológicas e as linhas de fraqueza estão associadas a freqüentes rupturas de gradientes, ao longo dos perfis longitudinais dos rios. (BIGARELLA et al., 1994, p. 77)

Dessa maneira, os compartimentos geomorfopedológicos representam os escalonamentos (degraus) internos da bacia e indicam, grosso modo, variação da energia potencial. As declividades entre 0 a $12 \%\left(\leq 7^{\circ}\right)$ estão presentes em $30 \%$ da área da bacia, principalmente nos setores de Terraço Fluvial, Patamares, Topos e subsidiariamente em alguns setores de Vertente convexa. As classes de declividade entre 12 a $30 \%\left(7^{\circ}\right.$ a $\left.17^{\circ}\right)$ respondem por $49,7 \%$ da área da bacia. Essas declividades são mais freqüentes nos segmentos de Vertentes convexas geralmente em setores laterais aos Patamares. (THOMAZ, 2005a)
As declividades $\geq 30 \%\left(\geq 17^{\circ}\right.$ ) ocupam $20,25 \%$ da área da bacia. Elas são representadas em geral por vertentes curtas marcando ruptura brusca de declive entre um estrato de basalto e outro; dessa forma, esse segmento forma extensas faixas contornando os Patamares estruturais. Enfim, os terrenos da bacia do Rio Guabiroba possuem declividade predominante média (12 a $20 \%$ ) a média/alta (20 a $30 \%$ e $\geq 30 \%$ ). Essas três classes acumulam $70 \%$ da área da bacia. (THOMAZ, 2005a)

No Domínio dos Planaltos Subtropicais com Araucárias, a decomposição química é intensa, principalmente nas áreas de menor altitude. Entre os solos dessa área, estão os solos brunos ácidos e solos lateríticos com baixa porcentagem de bases trocáveis. (BIGARELLA, 1994, p. 106)

A bacia do Rio Guabiroba está inserida numa grande unidade em que predomina a associação de solos Litólicos Álicos (Neossolos Litólicos) e Cambissolos Álico, ambos com horizonte A proeminente, textura argilosa fase pedregosa, sob domínio da floresta subtropical subperenifólia. O relevo dessa unidade é predominantemente forte ondulado a montanhoso, com declividade 
THOMAZ, E. L. Dinâmica do uso da terra e degradação do solo na bacia do Rio Guabiroba - Guarapuava/PR

superior a $40 \%$. Devido às características descritas, essa unidade apresenta suscetibilidade à erosão muito forte, bem como é predisposta a deslizamentos e desmoronamentos. (MENDES; CASTRO, 1984)

Outra unidade possível é formada pela associação de Latossolo Bruno Álico (relevo suave ondulado 3 a $8 \%$ ) e Cambissolo Álico (relevo ondulado $20 \%$ ). O horizonte $A$ é proeminente e a textura é argilosa. Possui suscetibilidade moderada à erosão quando predomina o Latossolo e forte quando predomina o Cambissolo (MENDES; CASTRO, 1984). Essa unidade é restrita ao Terraço Fluvial, Patamares e setores de vertentes convexas menos declivosas. Grande parte do espessamento dos solos no sopé de vertente e no Terraço Fluvial é resultado do transporte de material proveniente de montante (coluvionamento).

O clima de Guarapuava está sob o domínio da zona extratropical, o que resulta em temperaturas com caráter mesotérmico (MONTEIRO, 1963, apud THOMAZ; VESTENA, 2003). A temperatura anual média é $17,1 \pm 0,47^{\circ} \mathrm{C}$, o inverno é frio e o verão é amenizado pelas altitudes, a evaporação média anual é de $835,1 \pm 123,9 \mathrm{~mm}$. As chuvas são abundantes e distribuídas ao longo do ano, com média anual 1953,8 389,7 mm (série 1976-2002); desse modo, não se distingue um período seco. (THOMAZ; VESTENA, 2003)

A ocupação da Região Centro-Sul do estado do Paraná teve uma ligação muito forte com a exploração dos recursos naturais, em que se destacam "os ciclos econômicos" como tropeirismo, erva-mate, madeira, exploração/sistema faxinal ${ }^{3}$ e agricultura comercial. A organização do espaço regional (e, por conseguinte, a área em estudo), esteve intimamente ligada ao processo de apropriação dos recursos naturais, representados na forma dos ciclos econômicos (CHANG, 1988). Dessa forma, esse processo foi um dos principais agentes transformadores da paisagem regional, especialmente da cobertura vegetal, influenciando sobremaneira o sistema ambiental da área de estudo.

\section{MATERIAL E MÉTODO}

\section{MAPEAMENTO DO MEIO BIOFÍSICO NA ESCALA DE 1:10000}

O trabalho de mapeamento deu suporte às atividades de avaliação do meio biofísico (ensaios e monitoramento), bem como ao acompanhamento das atividades agrícolas na bacia do rio Guabiroba. As principais cartas geradas para esse estudo foram clinográfica, unidades geomorfopedológicas (relevo-solo), perfis e uso da terra. Essas cartas não são apresentadas neste trabalho devido às limitações de espaço e por se configurarem em uma etapa intermediária da pesquisa. Entretanto, o procedimento metodológico para o mapeamento e a caracterização das unidades de terras delimitadas no âmbito da bacia do Rio Guabiroba que deu suporte a esta pesquisa pode ser verificado em Thomaz (2005a, b).

\section{ATIVIDADES EM AGRICULTURA DE SUBSISTÊNCIA}

O monitoramento sistemático em campo foi realizado entre novembro de 2001 a maio de 2004. Nesse período, acompanharam-se todas as fases da condução da lavoura, da roçada da terra à colheita. A partir das observações sistemáticas, elaborou-se o calendário agrícola da agricultura de subsistência, reconheceramse as atividades agrícolas, o padrão do uso da terra, a degradação do meio biofísico e o nível tecnológico geral no âmbito da bacia do Rio Guabiroba, entre outros elementos envolvidos.

\section{AVALIAÇÃO DE SERRAPILHEIRA ESTOCADAE RESÍDUO ADICIONADO POR CULTURA}

A avaliação da serrapilheira estocada e do resíduo adicionado por cultura foi realizada por meio de um quadro de metal com $625 \mathrm{~cm}^{2}$. O quadro era arremessado, coletando-se a amostra de forma aleatória. Ao todo foram coletadas 15 amostras em cada uso da terra. Posteriormente, o material foi secado em estufa a $60^{\circ} \mathrm{C}$ e pesado. O resíduo adicionado pela cultura de milho em agricultura de subsistência foi estimado a partir da mensuração de material (restolho) avaliado em quinze covas.

\section{ANÁLISE FÍSICA DE SOLO (RESISTÊNCIA)}

Utilizou-se um penetrômetro de bolso (Pocket Soil Penetrometer $\mathrm{H}-4200$ ), para verificação da resistência do solo, de acordo com Thomaz e Ross, (2003). Os ensaios com esse instrumento foram realizados após período de chuva suficiente para molhar o topo e profundamente os horizontes do solo. Todavia, as coletas foram realizadas em torno 2 a 3 dias após a chuva, para que o solo atingisse a capacidade de campo. (REICHARDT, 1990)

3 Sistema familiar e de caráter coletivo no uso da terra para a produção animal (sistema de "criadouro comum", onde os animais são criados à solta no interior da floresta). (CHANG, 1988, p. 13) 
THOMAZ, E. L. Dinâmica do uso da terra e degradação do solo na bacia do Rio Guabiroba - Guarapuava/PR

\section{A AVALIAÇÃO DA RESISTÊNCIA DE MATERIAL FOI REALIZADA DE DUAS MANEIRAS:}

a) na superfície do solo (topo do solo): foram tomados usos representativos (freqüência/ área) na área de estudo, processo de estratificação, posteriormente dentro das unidades da terra coletou-se ao acaso 31 amostras; devido à relativa facilidade de coleta, a superfície do solo (topo) teve maior diversidade de usos avaliados;

b) em profundidade por meio de trincheiras: foram tomados usos representativos na área de estudo, processo de estratificação, posteriormente dentro das unidades da terra escavou-se 3 trincheiras ao acaso; cada trincheira possuía dimensões médias de $50 \mathrm{~cm}$ de largura por $60 \mathrm{~cm}$ de profundidade; a trincheira foi subdividida em três profundidades: $0-10 \mathrm{~cm}$, 20-30 cm e 40-50 cm; tal procedimento buscou correspondência mínima com os horizontes diagnósticos do solo e profundidade de práticas agrícolas; em seguida, coletaram-se ao acaso 7 amostras em cada profundidade, de modo que, em cada profundidade, somando-se as três trincheiras, fossem obtidas no mínimo 21 amostras.

\section{ANÁLISE FÍSICA DE SOLO (DENSIDADE APARENTE E POROSIDADE TOTAL)}

Para se retirar as amostras indeformadas, foram utilizados anéis volumétricos com $95,5 \mathrm{~cm}^{3}$. Foram retiradas 9 amostras em cada profundidade. No laboratório, as amostras foram preparadas e levadas para secar em estufa a $105^{\circ} \mathrm{C}$ por 24 horas (EMBRAPA, 1997). A obtenção dos parâmetros físicos como densidade aparente e porosidade total foram obtidas de acordo com Reichardt (1990)

\section{INFILTRAÇÃO DE ÁGUA NO SOLO}

Para medir a infiltração de água na superfície do solo, foi utilizado um infiltrômetro com anéis duplos. O equipamento é composto por dois reservatórios de água, com capacidade de 6,3 litros em cada um deles. Um dos reservatórios fornece água para o anel externo, com $20 \mathrm{~cm}$ de diâmetro, e o outro para o anel interno, com $10 \mathrm{~cm}$ de diâmetro, em que é medida a infiltração. Durante a mensuração da infiltração, a água é fornecida ao mesmo tempo aos dois anéis. O uso de anéis duplos busca diminuir o efeito de dispersão lateral da água durante o experimento. Os ensaios foram conduzidos ao acaso nos principais sistemas de uso durante 1 hora. (THOMAZ e HOMIAK, 2002)

\section{ANÁLISE ESTATÍSTICA}

Os dados foram tabulados e tratados por meio do software Excel 2000. A análise dos dados envolveu: 1) estatística descritiva; 2) análise de variância (ANOVA); 3) comparação de médias e estabelecimento de diferença mínima significativa (Teste de Tukey). $O$ emprego das técnicas e análises estatísticas seguiu as recomendações e os procedimentos contidos em Vieira (1999).

\section{RESULTADOS E DISCUSSÃO}

\section{DINÂMICA DO USO DA TERRA}

O uso da terra, na bacia do Rio Guabiroba, apresenta um padrão em forma de mosaico. A diversidade de usos, bem como os compartimentos geomorfológicos bem distintos, formam áreas em forma de manchas com limites bem definidos (abrupto) (Figuras 2e 3). Esse mosaico sobrepõese ao hidrossistema formado por rios perenes, intermitentes e efêmeros. Por sua vez, as estradas, os carreadores e os caminhos se sobrepõem ao sistema de drenagem e aos diversos usos da terra, como será visto adiante. Formase, assim, um padrão espacial com manchas irregulares conectadas/recortadas por corredores tortuosos ou lineares que influencia a morfodinâmica da bacia.

De maneira geral, a maioria das terras possui restrições geomorfopedológicas (vertentes declivosas e solos rasos). As áreas mecanizadas se restringem aos patamares e especialmente no setor de terraço fluvial com declives inferiores a $10 \%$ e solos com profundidade efetiva em torno de $1,5 \mathrm{~m}$. As pastagens se estendem por todos os compartimentos, contudo são mais freqüentes nas vertentes convexas com declive superior a $20 \%$. Nessas áreas, os solos possuem diversos graus de pedregosidade/rochosidade e a profundidade efetiva varia de 0,25 a $0,50 \mathrm{~m}$.

A agricultura de subsistência é praticada em terras geralmente declivosas superiores a $20 \%$ (setores convexos e retilíneos) (Figuras 2 e 3 ). Nesses setores, as terras apresentam pedregosidade e rochosidade variadas e a profundidade efetiva do solo fica entre 0,25 a 0,50 m. 
Na Figura 2, observa-se a estrutura e as características de uma propriedade, situação média, em que é praticada a agricultura de subsistência. Além disso, é possível verificar o padrão de uso da terra comentado anteriormente. Essa unidade de terra é delimitada na parte superior da vertente (espigão) por um patamar convexo alongado que possui declive da direita para esquerda da figura. Essa é uma forma típica de divisor interno da bacia do rio Guabiroba.

\section{FIGURA 2 - ESTRUTURA E CARACTERÍSTICAS DE UMA PROPRIEDADE RURAL}

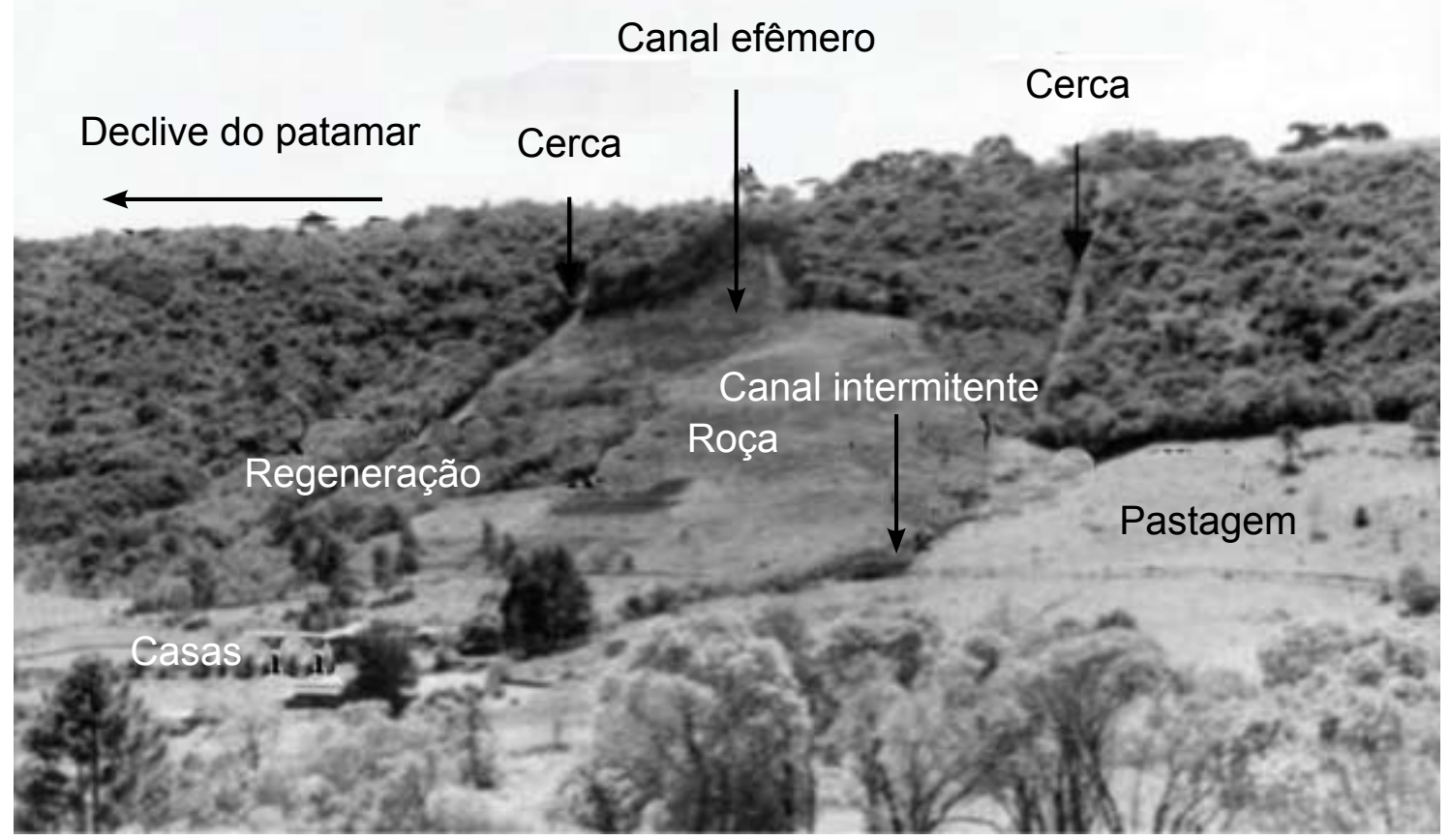

FONTE: Foto de THOMAZ, E. L. (Abril, 2003).

Lateralmente, o patamar apresenta segmentos de vertentes retilíneo e convexo, seguindo para o fundo do vale formando uma concavidade (local) gradativa até o segmento do terraço fluvial, setor com menor declividade. No esquema, observam-se as cercas laterais e internas delimitando as glebas. Na parte superior dentro do limite da propriedade e se estendendo para fora, há uma capoeira com estágio superior de regeneração do que a que se observa internamente no limite da propriedade.

Constatam-se ainda internamente duas áreas com roça, uma próxima à transição do terraço fluvial e outra na parte superior da vertente. Nesse setor retilíneo/convexo, o declive é superior a $30 \%$ e apresenta pedregosidade; além disso, a profundidade efetiva do solo varia de 0,25 a 0,50 m. Com essas características, a unidade de terra possui o que chamamos anteriormente de restrições geomorfopedológicas; por fim, no sistema de capacidade de uso, ela se insere na aptidão imprópria para qualquer tipo de cultivo, mesmo reflorestamento comercial. (LEPSCH et al., 1991).

Outro aspecto diz respeito ao sistema de drenagem interno, haja vista a presença de canais intermitentes e efêmeros, sendo que ambos dissecam lateralmente o patamar e, por conseguinte, as terras agrícolas. Essa rede de drenagem desempenha papel importante na circulação de água e sedimentos em setores de vertentes declivosas com solos rasos, uma vez que essa característica é freqüente em toda a bacia.

Anteriormente, verificaram-se os aspectos de uma unidade de terra em que é praticada a agricultura de subsistência; contudo, faz-se necessário o entendimento do ritmo das atividades agrícolas para melhor caracterizar o inter-relacionamento entre essas atividades e a dinâmica do meio biofísico. 
No Quadro 1, é apresentada uma situação que simula as seqüências das práticas agrícolas, que têm início em um ano e término em outro. Procurou-se representar as atividades agrícolas em relação à estação do ano em que elas ocorrem. Nesse sentido, o preparo da terra (roça) é feito no período de inverno, momento em que o agricultor escolhe uma gleba que estava em pousio. A capoeira é derrubada com foice e machado. O material é deixado solto sobre a terra para secar os galhos e folhas. Posteriormente, é feito o aceiro (limpeza) para evitar que o fogo se espalhe para áreas adjacentes (Figura 3 a). Em geral, a área é queimada no período da manhã ou da tarde.

\section{FIGURA 3 - MANEJO DA TERRA POR MEIO DO USO DE FOGO: A) AGRICULTORES, SOBRE ACEIRO, QUEI- MANDO CAPOEIRA; B) AGRICULTORES PLANTANDO NA CINZA, AO FUNDO OBSERVAM-SE LIMITES ABRUPTOS DAS GLEBAS.}
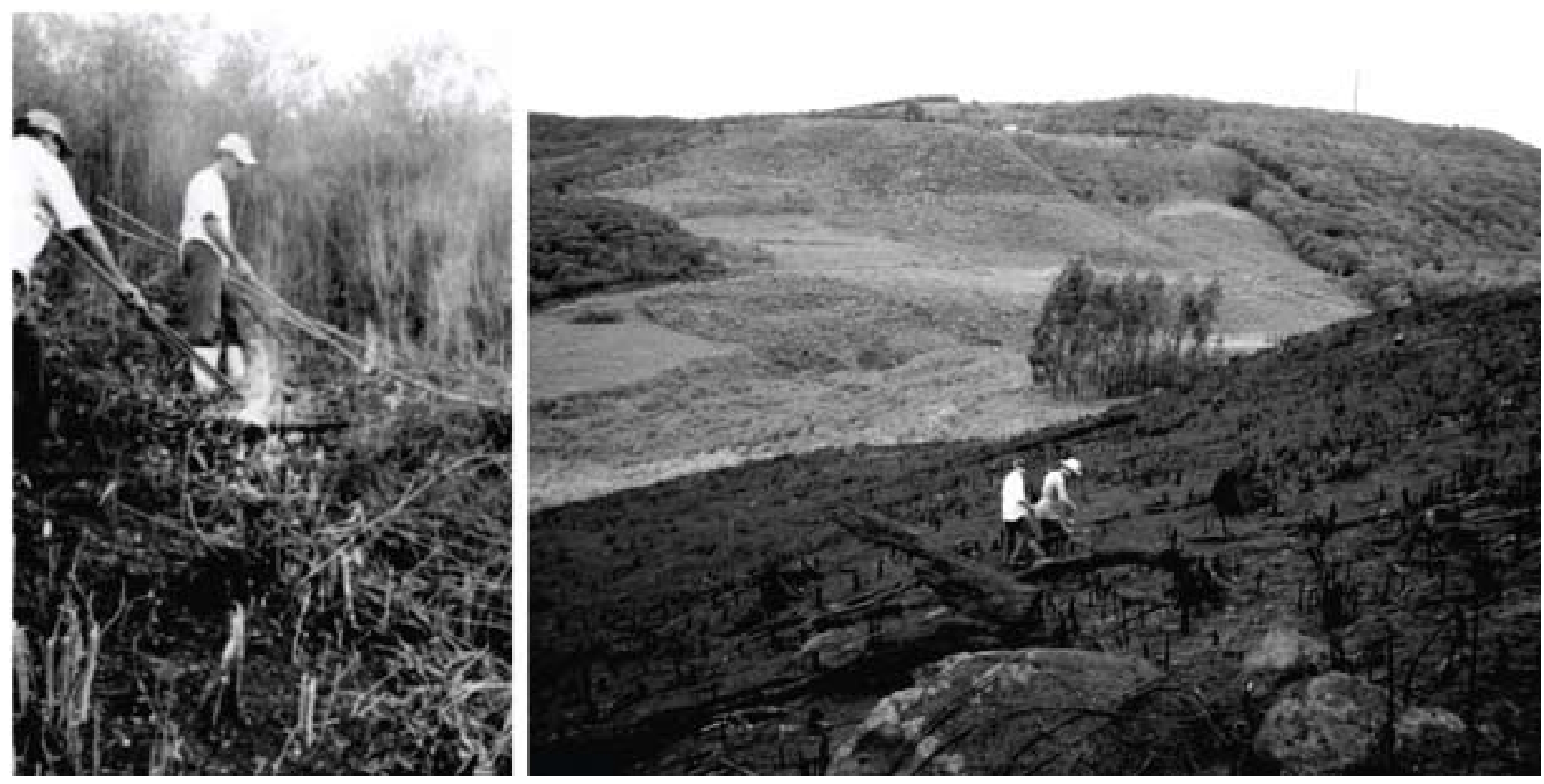

FONTE: Fotos de THOMAZ, E. L. (Abr., 2003 e Nov., 2004)

Dessa forma, a capoeira é queimada no final do inverno e começo da primavera; em seguida, é feito o plantio na cinza, em meados da primavera (Figura $3 \mathrm{~b}$ ). A semeadura é feita com matraca (plantadeira manual) e as linhas da cultura acompanham o sentido transversal do declive. Os tratos culturais são feitos com capina manual ou com herbicida, por meio de máquina costal. Nesse tipo de cultivo, não ocorre a correção do solo com calcário nem o uso de adubo no plantio ou em cobertura. Contudo, utiliza-se semente híbrida (comercial), notadamente para o cultivo de milho.

O desenvolvimento da cultura ocorre na estação "chuvosa" e quente. A colheita do feijão começa no verão, enquanto a colheita do milho ocorre geralmente no outono e começo do inverno. Após a colheita, a terra é deixada em pousio, dando início a um novo ciclo de regeneração.
O tempo médio de pousio varia de 3 a 5 anos; no entanto, quando o agricultor dispõe de poucas terras, esse tempo de espera, bem como o rodízio, acaba não ocorrendo. Destaca-se que a agricultura mecanizada segue calendário semelhante, com atividades na primavera/verão e com cultivo de inverno (trigo, aveia etc.) ou rodízio na forma de pastoreio.

A partir dessa análise, conclui-se que muitas unidades de terras seguem um ritmo em que a cobertura vegetal confere proteção ao solo durante certo tempo. Em contrapartida, quando ocorre a derrubada da capoeira, essa proteção decai, culminando com a mínima proteção quando ocorre a queimada da cobertura morta no início da primavera. Posteriormente, com o desenvolvimento da cultura em meados da primavera e principalmente no verão, a terra fica um pouco mais protegida. (Figura 4) 


\begin{tabular}{|c|c|c|c|c|c|c|c|c|c|c|c|c|c|c|c|}
\hline & \multicolumn{7}{|c|}{ ANO 1} & \multicolumn{8}{|c|}{ ANO 2} \\
\hline \multirow{9}{*}{$\begin{array}{l}\text { Atividades } \\
\text { agrícolas }\end{array}$} & Jun. & Jul. & Ago. & Set. & Out. & Nov. & Dez. & Jan. & Fev. & Mar. & Abr. & Maio & Jun. & Jul. & Ago. \\
\hline & \multicolumn{5}{|c|}{ Preparo da terra (roça) } & & & & & & & & & & \\
\hline & & & \multicolumn{4}{|c|}{ Queimada } & & & & & & & & & \\
\hline & & & & \multicolumn{3}{|c|}{ Plantio na cinza } & & & & & & & & & \\
\hline & & & & & \multicolumn{5}{|c|}{$\begin{array}{c}\text { Tratos culturais } \\
\text { (capina/herbicida) }\end{array}$} & & & & & & \\
\hline & & & & & & & & \multicolumn{4}{|c|}{ Colheita/feijão } & & & & \\
\hline & & & & & & & & & \multicolumn{5}{|c|}{ Colheita/milho } & & \\
\hline & & & & & \multicolumn{6}{|c|}{ Estágio vegetativo das culturas } & & & \multicolumn{3}{|c|}{$\begin{array}{l}\text { Regeneração } \\
\text { da terra }\end{array}$} \\
\hline & \multicolumn{15}{|c|}{ Nova área é introduzida no rodízio de terras } \\
\hline $\begin{array}{l}\text { Estações } \\
\text { do ano }\end{array}$ & \multicolumn{3}{|c|}{ "Seca" (fria/geadas) } & \multicolumn{3}{|c|}{$\begin{array}{c}\text { Chuvosa } \\
\text { (moderadamente } \\
\text { quente) }\end{array}$} & \multicolumn{3}{|c|}{$\begin{array}{l}\text { Chuvosa } \\
\text { (quente) }\end{array}$} & \multicolumn{3}{|c|}{$\begin{array}{l}\text { Redução das } \\
\text { chuvas (geadas) }\end{array}$} & \multicolumn{3}{|c|}{$\begin{array}{c}\text { "Secas" } \\
\text { (fria/geadas) }\end{array}$} \\
\hline
\end{tabular}

QUADRO 1 - CALENDÁRIO AGRÍCOLA APROXIMADO EM AGRICULTURA DE SUBSISTÊNCIA

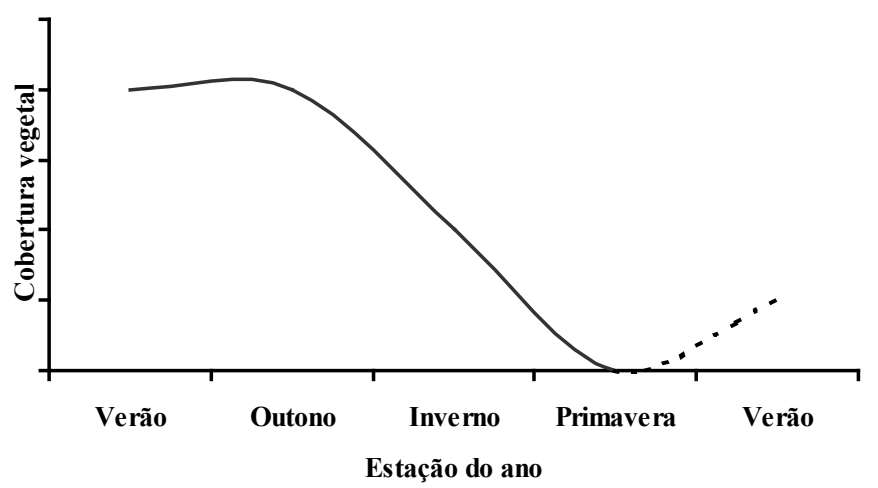

FONTE: Organizado por THOMAZ, E. L. (2003)

\section{FIGURA 4 - ESQUEMA HIPOTÉTICO DA DINÂMICA DA COBERTURA VEGETAL E PROTEÇÃO AO SOLO SOB AGRICULTURA DE SUBSISTÊNCIA}

No fim do ciclo da cultura, ocorre a colheita, e os restos culturais são deixados sobre o solo; além disso, a vegetação espontânea começa a formar uma sucessão secundária, regenerando a cobertura vegetal até a terra ser recoberta por capoeira. Em alguns casos, a terra fica em descanso por quase uma década.

\section{USO DA TERRA: SERRAPILHEIRA E RESÍDUO DE CULTURA ESTOCADO NA SUPERFÍCIE DO SOLO}

Foram avaliados os estoques de cobertura morta (serrapilheira e restos culturais) em diversos tipos de usos, no intuito de comparar a variação na quantidade de material em cada uso (Tabela 1). A literatura enfoca amplamente a importância da cobertura vegetal na proteção do solo contra os agentes erosivos. No entanto, como visto anteriormente, as atividades agrícolas na bacia do rio Guabiroba criam um padrão espacial em forma de mosaico (manchas) nas terras agrícolas e, por conseguinte, isso se reflete na cobertura do solo, indicando estágios diferentes de regeneração e principalmente de proteção ao solo. 
THOMAZ, E. L. Dinâmica do uso da terra e degradação do solo na bacia do Rio Guabiroba - Guarapuava/PR

TABELA 1 - ESTIMATIVA DE MATÉRIA SECA ESTOCADA EM DIFERENTES USOS DA TERRA (kg/m²)

\begin{tabular}{lc}
\hline \multicolumn{1}{c}{ USO DA TERRA } & $\mathrm{kg} / \mathrm{m}^{2}$ \\
\hline $\begin{array}{l}\text { 1. Capoeira }(\approx 2,5 \text { anos em regeneração) } \\
\text { 2. Capoeira }(\approx 8 \text { anos em regeneração) }\end{array}$ & $1,0,78 \pm 0,18^{2}$ \\
3. Capoeira com predomínio de bambu $(\approx 18$ anos em regeneração) & $0,88 \pm 0,29$ \\
4. Floresta secundária (Faxinal) $(\approx 50$ anos de uso) & $1,25 \pm 0,59$ \\
5. Reflorestamento com eucalipto $(\approx 6$ anos $)$ & $1,40 \pm 0,24$ \\
6. Capoeira com predomínio de bracatinga $(\approx 30$ anos em regeneração) & $1,41 \pm 0,37$ \\
7. Floresta com araucária $(\approx 50$ anos em regeneração) & $2,26 \pm 0,56$ \\
8. Floresta secundária, sem araucária $(\approx 25$ anos em regeneração) & $1,29 \pm 0,41$ \\
9. Restos culturais de milho em agricultura de subsistência & $0,99 \pm 0,38$ \\
\hline
\end{tabular}

Notas: ${ }^{1}$ Média de 15 amostras; ${ }^{2}$ Desvio padrão.

Dados coletados e trabalhados por THOMAZ, E. L. (2004).

Verificou-se uma grande variabilidade na quantidade de material estocado, de acordo com o uso da terra. A maior quantidade foi registrada em floresta com araucária com $22,6 \mathrm{t} / \mathrm{ha}$ e a menor quantidade foi $7,84 \mathrm{t} / \mathrm{ha}$ em capoeira com 2,5 anos de regeneração. Tal quantidade representa quase três vezes menos material do que na área com floresta. Soma-se a isso a espessura da serrapilheira, que na floresta era em média de 3 a $5 \mathrm{~cm}$, e se distribuía de forma homogênea, enquanto que na capoeira a espessura era em torno de $1 \mathrm{~cm}$, mas o material recobria o solo de maneira irregular (manchas). No geral, as capoeiras e as florestas secundárias, apesar do tempo em regeneração, algumas por mais de 20 anos, tiveram em média metade da serrapilheira quando comparadas com a floresta de araucária próxima à condição natural (uso 7).

A área com floresta secundária (Faxinal) registrou 12,5 t/ha, valor próximo ao encontrado em outros usos com capoeira e florestas secundárias. No entanto, chama a atenção nesse uso a variabilidade da cobertura de serrapilheira $(46,9 \%)$. No intervalo de confiança estimado, o valor ficou entre 9,2 t/ha e 15,7 t/ha; esse padrão se deve ao desbaste realizado no interior dessa floresta. Algumas áreas não possuem o sub-bosque e o estrato herbáceo, ficando recobertas apenas com o dossel formado pelas araucárias ou por outras espécies. Isso pode reduzir o adicionamento de serrapilheira ao solo da floresta; além disso, a distribuição da serrapilheira é irregular internamente. A área de eucalipto teve o menor coeficiente de variação $(17,3 \%)$, o que indica que a área com reflorestamento apresentou recobrimento relativamente homogêneo, devida não haver diversidade de espécies, bem como à inexistência de estratificação interna (sub-bosque). Em termos de quantidade estocada, foi equivalente à das demais áreas com florestas secundárias e capoeiras.

$\mathrm{Na}$ cultura anual, o resíduo de milho foi superior ao de alguns usos com capoeira. Nas capoeiras, florestas secundárias, floresta com araucária e Faxinal, a cobertura de serrapilheira confere proteção ao solo, considerando ainda que a precipitação tem que atravessar o dossel e estratos inferiores da cobertura vegetal para, posteriormente, transpor a serrapilheira. No caso do milho, muitos agricultores, após a colheita, não derrubam a palhada e dessa forma as plantas ficam em pé (vertical). Acredita-se que, com esse procedimento, elas protegem menos o solo, ao passo que, se fossem espalhadas, protegeriam bem mais. 
THOMAZ, E. L. Dinâmica do uso da terra e degradação do solo na bacia do Rio Guabiroba - Guarapuava/PR

\section{USO DA TERRA E INFLUÊNCIA NO MATERIAL SUPERFICIAL AVALIADO EM TRINCHEIRA}

\section{RESISTÊNCIA}

Analisa-se agora a influência do uso da terra sobre as características físicas dos solos, especialmente resistência, densidade aparente e porosidade total. $\mathrm{Na}$ Tabela 2, verifica-se a resistência de materiais em 7 usos da terra e em 3 profundidades. No geral, em áreas de pastagem ou agricultura em pousio, a resistência tendeu a diminuir com a profundidade, ao contrário do que foi verificado nos 3 primeiros usos, em que a parte superficial registrou as menores resistências.

$\mathrm{Na}$ agricultura mecanizada (uso 1), a análise foi feita pouco depois de área ter passado por aração/ gradagem. Observa-se que de 0 a $10 \mathrm{~cm}$ a resistência foi de $0,21 \mathrm{kgf} / \mathrm{cm}^{2}$, passando de 20 a $30 \mathrm{~cm}$ para
$1,36 \mathrm{kgf} / \mathrm{cm}^{2}$, isto é, $547,6 \%$ superior que a resistência anterior; já na profundidade de 40 a $50 \mathrm{~cm}$, houve um decréscimo para $1,17 \mathrm{kgf} / \mathrm{cm}^{2}$ ou $16,2 \%$ inferior ao da profundidade anterior.

Esse comportamento indica que a mecanização deixa a parte superficial do solo mais solta, devido à ação do implemento; no entanto, a camada mais profunda marca o limite de aração (pé-de-grade e pé-de-arado), o solo fica mais resistente. Por fim, na última profundidade, tende a diminuir a resistência do solo, o que indica a diminuição do efeito dos implementos agrícolas.

De modo semelhante à agricultura mecanizada em pousio (uso 4) e campo sujo (uso 6), apresenta a influência da mecanização. Entretanto, após o preparo da terra para o plantio, a camada superficial fica solta até a profundidade de $20 \mathrm{~cm}$. Posteriormente, com o fim do ciclo da cultura de verão, a terra permanece em pousio até a próxima safra ou é semeada com aveia para pastoreio. Dessa forma, consta-se que a camada superficial tende a aumentar a resistência.

\section{TABELA 2 - RESISTÊNCIA DO SOLO (kgf/cm²), DE ACORDO COM O USO DA TERRA E PROFUNDIDADE}

\begin{tabular}{|c|c|c|c|}
\hline \multirow[b]{2}{*}{ Uso da terra/forma de relevo } & \multicolumn{3}{|c|}{ PROFUNDIDADE (cm) } \\
\hline & $0-10$ & $20-30$ & $40-50$ \\
\hline 1 - Agricultura mecanizada (Convexo) & ${ }^{1} 0,21 \pm 0,23^{2} a^{3}$ & $1,36 \pm 0,33 a$ & $1,17 \pm 0,38 a b$ \\
\hline 2 - Floresta com araucária (Terraço fluvial) & $0,30 \pm 0,23 a$ & $1,49 \pm 0,37 a$ & $0,88 \pm 0,23 a$ \\
\hline 3 - Agricultura de subsistência/pousio (Retilíneo) & $0,55 \pm 0,34 a$ & $1,83 \pm 0,36 b$ & $1,63 \pm 0,33 c$ \\
\hline 4 - Agricultura mecanizada/pousio (Patamar) & $1,50 \pm 0,87 b$ & $1,57 \pm 0,43 a b$ & $1,30 \pm 0,46 b$ \\
\hline 5 - Pastagem (Convexo) & $1,70 \pm 0,89 b$ & $1,37 \pm 0,34 a$ & $1,14 \pm 0,15 a b$ \\
\hline 6 - Campo sujo/culturas anuais/pastoreio (Convexo) & $1,98 \pm 0,35 \mathrm{bc}$ & $1,57 \pm 0,36 a b$ & $1,36 \pm 0,38 b c$ \\
\hline 7 - Pastagem (Convexo) & $2,29 \pm 0,46 c$ & $1,88 \pm 0,33 b$ & $1,65 \pm 0,37 c$ \\
\hline 8 - Pastagem degradada (Terraço fluvial) & $3,07 \pm 0,65 d$ & $2,25 \pm 0,49 c$ & $2,05 \pm 0,41 d$ \\
\hline
\end{tabular}

Notas: ${ }^{1}$ Média de 21 amostras; ${ }^{2}$ Desvio Padrão; ${ }^{3}$ Coluna seguida de mesma letra não difere significativamente pelo Teste de Tukey a a5\%. Dados coletados e trabalhados por THOMAZ, E. L. (2004).

Por exemplo, a agricultura em pousio (uso 4), na profundidade de 20 a 30, foi apenas $4,7 \%(1,57 \mathrm{kgf} /$ $\mathrm{cm}^{2}$ ) mais resistente do que a profundidade de 0 a 10 $\mathrm{cm}\left(1,50 \mathrm{kgf} / \mathrm{cm}^{2}\right)$, enquanto que na profundidade de 40 a $50 \mathrm{~cm}\left(1,30 \mathrm{kgf} / \mathrm{cm}^{2}\right)$ foi $20,8 \%$ menos resistente que a profundidade anterior. A mecanização, nos casos observados, tende, após pousio ou pastoreio, a aumentar a resistência das camadas superficiais, a homogeneizar o perfil na profundidade avaliada e a predispor o topo do solo ao encrostamento superficial.
As pastagens apresentaram a camada superficial com maior resistência (usos 5 e 7) de modo semelhante às áreas de agricultura (usos 4 e 6). Ambas as pastagens apresentaram tendência de decréscimo da resistência com o aumento da profundidade. No caso da pastagem (uso 5), apresentou de 0 a $10 \mathrm{~cm} \mathrm{1,70} \mathrm{kgf/cm²,} \mathrm{24,1 \%} \mathrm{superior} \mathrm{ao}$ registrado na profundidade de 20 a $30 \mathrm{~cm}\left(1,37 \mathrm{kgf} / \mathrm{cm}^{2}\right)$; por outro lado, a resistência nessa profundidade foi $20,2 \%$ superior à obtida na profundidade seguinte $\left(1,14 \mathrm{kgf} / \mathrm{cm}^{2}\right)$. A resistência entre $0-10 \mathrm{~cm}$ foi $49,1 \%$ superior ao registrado na profundidade entre $40-50 \mathrm{~cm}$. 
THOMAZ, E. L. Dinâmica do uso da terra e degradação do solo na bacia do Rio Guabiroba - Guarapuava/PR

A pastagem degradada (uso 8) foi uma área em que houve remoção do horizonte superficial do solo em torno de $40 \mathrm{~cm}$ (ação antrópica e erosão). Dessa forma, a avaliação seguiu as mesmas profundidades, contudo deve-se considerar a profundidade do material removido; além disso, o local apresentava baixa cobertura do solo, entre 10 a $15 \%$. Devido às características supramencionadas, esse uso foi o que apresentou a maior resistência em todas as profundidades avaliadas. Assim, o topo do solo $(0-10 \mathrm{~cm})$ foi $49,8 \%$ mais resistente do que o registrado na última profundidade, sendo que entre a profundidade de $20-30 \mathrm{~cm}$ e a de $40-50 \mathrm{~cm}$ a diferença foi de apenas $9,8 \%$. O topo do solo dessa área apresentou tendência ao encrostamento superficial.

\section{DENSIDADE APARENTE}

A Tabela 3 apresenta a densidade aparente em diferentes usos da terra e profundidades. De maneira geral, observaram-se nas duas primeiras profundidades dois grupos com densidades diferentes. Essa diferença, no entanto, não foi observada na profundidade de $40-50 \mathrm{~cm}$, em que não ocorreu diferença significativa entre os usos. $O$ efeito do uso da terra (manejo) sobre a densidade aparente tendeu a decrescer do topo do solo para as partes mais profundas, sendo que de 40 a $50 \mathrm{~cm}$ não se constatou diferença entre eles.

\section{TABELA 3 - DENSIDADE APARENTE $\left(\mathrm{g} / \mathrm{cm}^{3}\right)$, DE ACORDO COM O USO DA TERRA E PROFUNDIDADE}

\begin{tabular}{|c|c|c|c|}
\hline \multirow[b]{2}{*}{ Uso da terra } & \multicolumn{2}{|c|}{ PROFUNDIDADE (cm) } & \multirow[b]{2}{*}{$40-50$} \\
\hline & $0-10$ & $20-30$ & \\
\hline 1 - Floresta secundária (Faxinal) (Convexo) & ${ }^{1} 1,03 \pm 0,11^{2} a^{3}$ & $1,18 \pm 0,11 b$ & $1,14 \pm 0,06 a$ \\
\hline 2 - Floresta com araucária (Terraço fluvial) & $1,04 \pm 0,10 a$ & $1,19 \pm 0,06 b$ & $1,09 \pm 0,09 a$ \\
\hline 3 - Pastagem (Convexo) & $1,05 \pm 0,05 a$ & $1,06 \pm 0,04 a$ & $1,09 \pm 0,03 a$ \\
\hline 4 - Agricultura mecanizada (Convexo) & $1,09 \pm 0,08 a b$ & $1,18 \pm 0,06 b$ & $1,13 \pm 0,07 a$ \\
\hline 5 - Pastagem (Convexo) & $1,10 \pm 0,03 a b$ & $1,11 \pm 0,06 a b$ & $1,10 \pm 0,05 a$ \\
\hline 6 - Pastagem degradada (Terraço fluvial) & $1,14 \pm 0,03 b$ & $1,12 \pm 0,03 a b$ & $1,13 \pm 0,04 a$ \\
\hline 7 - Agricultura mecanizada/Pousio (Patamar) & $1,19 \pm 0,06 b$ & $1,18 \pm 0,06 b$ & $1,06 \pm 0,04 a$ \\
\hline
\end{tabular}

Notas: ${ }^{1}$ Média de 9 amostras; ${ }^{2}$ Desvio Padrão; ${ }^{3}$ Coluna seguida de mesma letra não difere significativamente pelo Teste de Tukey a a $5 \%$.

A amplitude entre os usos, diferença entre a maior e menor densidade, demonstra que na primeira profundidade ela foi $15,4 \%$ superior, na segunda $12,3 \%$ e na última $7,5 \%$, isto é, com o aumento da profundidade, a diferença da densidade entre os usos diminui.

As pastagens (usos 3, 5 e 6) não apresentaram diferenças significativas de uma profundidade para outra. Contudo, a agricultura mecanizada (uso 4) apresentou uma densidade $8,3 \%$ superior na segunda profundidade, comparada com a obtida na primeira. Outro uso com agricultura mecanizada (uso 7) não apresentou diferença significativa nas duas primeiras profundidades, contudo, de 0-10 cm foi $12,3 \%$ mais denso se comparado ao registrado na última profundidade. Em ambas, esse comportamento pode estar ligado ao efeito da mecanização, da mesma forma quando se analisou a resistência do solo.

Os usos com florestas (usos 1 e 2) apresentaram suas maiores densidades na profundidade de 20-30 $\mathrm{cm}$. No caso do Faxinal, nessa profundidade houve presença de material grosseiro em decomposição, o que aumentou um pouco a densidade nesse local. A floresta com araucária (uso 2) também apresentou inicialmente maior densidade nessa profundidade; considerou-se como causa para maior densidade a agregação do solo, devido à presença de raízes superficiais. Entretanto, em uma das trincheiras, foi encontrado um pedaço de carvão, o que pode indicar que nessa área já tenha sido praticada agricultura ou ainda que houve transporte de material de montante, soterrando a camada superficial e originando uma camada truncada mais densa.

\section{POROSIDADE TOTAL}

A porosidade, (Tabela 4) apresenta resultados semelhantes aos obtidos nas análises da densidade, haja vista as estimativas da porosidade total terem sido feitas com os parâmetros físicos provenientes da densi- 
THOMAZ, E. L. Dinâmica do uso da terra e degradação do solo na bacia do Rio Guabiroba - Guarapuava/PR

dade aparente. Dessa forma, verificou-se que nas duas primeiras profundidades há dois grupos com porosidade distinta, principalmente entre 0 a $10 \mathrm{~cm}$. Por outro lado, entre 40 e $50 \mathrm{~cm}$ não ocorre diferença significativa na porosidade total.

\section{TABELA 4 - POROSIDADE TOTAL (\%), DE ACORDO COM O USO DA TERRA E PROFUNDIDADE}

\begin{tabular}{|c|c|c|c|}
\hline \multicolumn{4}{|c|}{ PROFUNDIDADE (cm) } \\
\hline Uso da terra & $0-10$ & $20-30$ & $40-50$ \\
\hline $\begin{array}{l}1 \text { - Floresta secundária } \\
\text { (Faxinal) (Convexo) }\end{array}$ & ${ }^{1} 61,2 \pm 6,6^{2} b^{3}$ & $55,4 \pm 4,3 a b$ & $57,0 \pm 2,2 a$ \\
\hline $\begin{array}{c}2 \text { - Floresta com araucária } \\
\text { (Terraço fluvial) }\end{array}$ & $60,8 \pm 6,0 \mathrm{~b}$ & $54,9 \pm 2,4 a$ & $58,7 \pm 3,3 a$ \\
\hline $\begin{array}{l}3 \text { - Pastagem } \\
\text { (Convexo) }\end{array}$ & $60,5 \pm 3,2 b$ & $59,9 \pm 1,4 b$ & $59,0 \pm 1,3 a$ \\
\hline $\begin{array}{c}4 \text { - Agricultura mecanizada } \\
\text { (Convexo) }\end{array}$ & $58,7 \pm 5,0 a b$ & $55,5 \pm 2,2 a b$ & $57,4 \pm 2,5 a$ \\
\hline $\begin{array}{l}5 \text { - Pastagem } \\
\text { (Convexo) }\end{array}$ & $58,5 \pm 1,8 a b$ & $58,3 \pm 2,3 a b$ & $58,6 \pm 1,7 a$ \\
\hline $\begin{array}{c}6 \text { - Pastagem degradada } \\
\text { (Terraço fluvial) }\end{array}$ & $57,2 \pm 2,0 \mathrm{ab}$ & $57,9 \pm 1,0 a b$ & $57,4 \pm 1,6 a$ \\
\hline $\begin{array}{c}7 \text { - Agricultura mecanizada/Pousio } \\
\text { (Patamar) }\end{array}$ & $55,1 \pm 4,0 a$ & $58,0 \pm 2,5 a b$ & $60,0 \pm 1,5 a$ \\
\hline
\end{tabular}

Notas: ${ }^{1}$ Média de 9 amostras; ${ }^{2}$ Desvio Padrão; ${ }^{3}$ Coluna seguida de mesma letra não difere significativamente pelo Teste de Tukey a a5\%. Dados coletados e trabalhados por THOMAZ, E. L. (2004).

A amplitude, diferença entre a maior e a menor porosidade, indica que na primeira profundidade ela foi $11,1 \%$, na segunda $4,7 \%$ e na última $5,3 \%$. Nesse parâmetro, enquanto em alguns usos a porosidade total aumentava com a profundidade, em outros ela diminuía. O exemplo mais significativo se verificou na agricultura mecanizada (uso 7), em que da primeira profundidade para a segunda a porosidade foi $5,3 \%$ superior e na seguinte, em comparação com a segunda profundidade, ela foi $3,5 \%$ superior. Finalmente, a porosidade registrada entre 40 e $50 \mathrm{~cm}$ foi em torno de $8,9 \%$ superior ao verificado entre 0 e $10 \mathrm{~cm}$. Portanto, a porosidade total aumentou à medida que a profundidade se tornou maior. Da mesma maneira que as observações anteriores, isso pode estar ligado ao efeito da mecanização.

\section{USO DA TERRA E INFLUÊNCIA NO MATERIAL AVALIADO NO TOPO DO SOLO}

\section{RESISTÊNCIA}

A seguir, apresentam-se as características superficiais do topo do solo acerca de sua resistência em 12 usos da terra (Quadro 2), e densidade aparente e porosidade total entre 0 a $5 \mathrm{~cm}$ em 16 usos da terra (Quadro 3 ). No geral, a resistência do topo do solo apresentou variabilidade, principalmente no que se refere à presença intercalada de pastagens e agricultura mecanizada como áreas com as maiores resistências (Quadro 2). 
THOMAZ, E. L. Dinâmica do uso da terra e degradação do solo na bacia do Rio Guabiroba - Guarapuava/PR

\begin{tabular}{|c|c|c|}
\hline USO DA TERRA & FORMA DE RELEVO (SEGMENTO) & RESISTÊNCIA $\left(\mathrm{kgf} / \mathrm{cm}^{2}\right)$ \\
\hline 1 - Capoeira em regeneração ( $\approx 3$ anos) & Retilíneo $(60 \%)$ & ${ }^{1} 0,50 \pm 0,20^{2} a^{3}$ \\
\hline 2 - Pousio pós-milho/agr. subsistência & Retilíneo $(60 \%)$ & $0,93 \pm 0,36 a b$ \\
\hline $\begin{array}{c}3 \text { - Culturas anuais soja e milho } \\
\text { (mecanizadas) }\end{array}$ & Convexo/terraço fluvial (6 a 15\%) & $1,37 \pm 0,63 b$ \\
\hline $\begin{array}{c}4 \text { - Pousio pós-milho e aveia/pastoreio } \\
\text { (mecanizados) }\end{array}$ & Patamar (5\%) & $1,47 \pm 0,60 \mathrm{~b}$ \\
\hline 5 - Cultivo de milho & Convexo (20 a $30 \%)$ & $2,28 \pm 1,16 \mathrm{c}$ \\
\hline 6 - Pastagem plantada (aração/gradagem) & Topo (10 a $15 \%)$ & $2,40 \pm 0,78 \mathrm{c}$ \\
\hline $\begin{array}{l}7 \text { - Culturas anuais e pastoreio } \\
\text { (mecanizadas) feijão }\end{array}$ & Convexo/terraço fluvial (8 a 15\%) & $2,46 \pm 1,08 \mathrm{c}$ \\
\hline 8 - Pastagem rasteira & Convexo (20 a $25 \%)$ & $2,65 \pm 0,90 \mathrm{c}$ \\
\hline $\begin{array}{l}9 \text { - Culturas anuais (plantio na } \\
\text { palha - mecanizadas) }\end{array}$ & Terraço fluvial $(6 \%)$ & $2,69 \pm 0,70 \mathrm{c}$ \\
\hline 10 - Pastagem rasteira & Convexo/terraço fluvial (8 a $20 \%$ ) & $2,79 \pm 0,85 c$ \\
\hline $\begin{array}{l}11 \text { - Culturas anuais (pastoreio) } \\
\text { (mecanizados) }\end{array}$ & Convexo/terraço fluvial (8 a 15\%) & $2,94 \pm 1,12 \mathrm{c}$ \\
\hline 12 - Pastagem degradada (erudibilidade) & Terraço fluvial (5 a 8\%) & $4,23 \pm 0,38 d$ \\
\hline
\end{tabular}

Notas: ${ }^{1}$ Média de 31 amostras; ${ }^{2}$ Desvio Padrão; ${ }^{3}$ Coluna seguida de mesma letra não difere significativamente pelo Teste de Tukey a $\alpha 5 \%$. Dados coletados e trabalhados por THOMAZ, E. L. (2004).

\section{QUADRO 2 - RESISTÊNCIA DO TOPO DO SOLO $\left(\mathrm{Kgf} / \mathrm{cm}^{2}\right)$, DE ACORDO COM O USO DA TERRA}

As áreas com agricultura mecanizada tiveram uma resistência ligeiramente maior do que as pastagens. Além disso, algumas áreas de agricultura mecanizada são utilizadas para pastoreio (uso misto), ocorrendo assim um nítido aumento de resistência superficial. Apenas os dois primeiros usos em agricultura de subsistência tiveram resistência bem inferior aos demais usos. De modo contrário, a pastagem degradada (uso 12) teve a maior resistência entre todos os usos.

Ao avaliar a diferença de resistência da capoeira em regeneração $0,50 \mathrm{kgf} / \mathrm{cm}^{2}$ (uso 1) e agricultura mecanizada $2,94 \mathrm{kgf} / \mathrm{cm}^{2}$ (uso 11), verifica-se que esta última teve uma capacidade de suporte $488 \%$ superior em relação à anterior. Conclui-se, portanto, que há grande variabilidade de resistência de materiais, de acordo com o uso da terra e manejo, bem como dentro das próprias classes de uso pastagem ou agricultura mecanizada.

\section{DENSIDADE APARENTE E POROSIDADE TOTAL}

No Quadro 3, constata-se que as pastagens tiveram densidade aparente menor e porosidade total maior do que os valores registrados nas áreas de agricultura mecanizada. Essa tendência pode ser devido ao maior número de raízes/estolões presentes nas amostras em áreas de pastagens, o que resulta numa menor densidade e, em contrapartida, aumenta a porosidade.

A maior diferença nos parâmetros analisados foi verificada entre o pousio, após a colheita de milho em área de terraço fluvial e a área de agricultura mecanizada (plantio direto) também no terraço fluvial. A densidade no uso 1 foi de $0,79 \mathrm{~g} / \mathrm{cm}^{3}$, enquanto que no uso 16 foi de $1,32 \mathrm{~g} / \mathrm{cm}^{3}$, ou seja, $67,1 \%$ mais denso. A porosidade no uso 1 foi $70,1 \%$ e no uso 16 foi de $50,1 \%$; nesse parâmetro, a porosidade foi $39,9 \%$ inferior no segundo uso. 
THOMAZ, E. L. Dinâmica do uso da terra e degradação do solo na bacia do Rio Guabiroba - Guarapuava/PR

\begin{tabular}{|c|c|c|c|}
\hline USO DA TERRA & $\begin{array}{l}\text { FORMA DE RELEVO } \\
\text { (SEGMENTO) }\end{array}$ & $\begin{array}{l}\text { DENSIDADE APARENTE } \\
\left(\mathrm{g} / \mathrm{cm}^{3}\right)\end{array}$ & POROSIDADE TOTAL (\%) \\
\hline 1 - Pousio pós-milho & Terraço fluvial/várzea (2\%) & ${ }^{1} 0,79 \pm 0,09^{2} a^{3}$ & $70,1 \pm 3,2 \mathrm{a}$ \\
\hline $\begin{array}{c}2 \text { - Capoeira em regeneração } \\
\text { ( } \approx 8 \text { anos })\end{array}$ & Convexo (15 a 20\%) & $0,83 \pm 0,09 a b$ & $68,6 \pm 3,3 a b$ \\
\hline $\begin{array}{l}3 \text { - Pousio pós-milho } \\
\text { (mecanizado) }\end{array}$ & $\begin{array}{l}\text { Convexo/terraço fluvial } \\
\qquad(10 \text { a } 15 \%)\end{array}$ & $0,95 \pm 0,06 \mathrm{~b}$ & $64,3 \pm 2,1 \mathrm{ab}$ \\
\hline 4 - Pastagem rasteira & Convexo (20 a $25 \%)$ & $0,96 \pm 0,08 b$ & $64,0 \pm 2,9 a b$ \\
\hline 5 - Pousio pós-milho & Retilíneo (60\%) & $1,01 \pm 0,12 b$ & $61,7 \pm 4,4 a b$ \\
\hline 6 - Pastagem alta & Convexo (15 a $20 \%)$ & $1,10 \pm 0,05 \mathrm{bc}$ & $58,6 \pm 2,0 \mathrm{ab}$ \\
\hline $\begin{array}{l}7 \text { - Pastagem plantada } \\
\text { (aração/gradagem) }\end{array}$ & Topo (10 a 15\%) & $1,10 \pm 0,05 \mathrm{bc}$ & $58,6 \pm 1,6 a b$ \\
\hline 8 - Pastagem rasteira & $\begin{array}{l}\text { Convexo/terraço fluvial } \\
\text { (8 a 20\%) }\end{array}$ & $1,16 \pm 0,09 \mathrm{c}$ & $56,4 \pm 2,9 \mathrm{~b}$ \\
\hline 9 - Pastagem rasteira & Convexo (15 a $20 \%$ ) & $1,19 \pm 0,07 \mathrm{c}$ & $54,9 \pm 2,8 \mathrm{bc}$ \\
\hline $\begin{array}{l}10 \text { - Pousio pós-milho e aveia/ } \\
\text { pastoreio (mecanizados) }\end{array}$ & Patamar (5\%) & $1,20 \pm 0,09 \mathrm{~cd}$ & $54,6 \pm 3,3 \mathrm{bc}$ \\
\hline $\begin{array}{l}11 \text { - Culturas anuais (soja e } \\
\text { milho) (mecanizadas) }\end{array}$ & $\begin{array}{l}\text { Convexo/terraço fluvial } \\
\qquad(6 \text { a } 15 \%)\end{array}$ & $1,22 \pm 0,05 \mathrm{~cd}$ & $53,8 \pm 1,8 b c$ \\
\hline 12 - Pastagem degradada & Terraço fluvial (5 a 8\%) & $1,24 \pm 0,05 \mathrm{~cd}$ & $53,1 \pm 2,0 \mathrm{c}$ \\
\hline 13 - Cultivo de milho & Convexo (20 a $30 \%)$ & $1,25 \pm 0,13 \mathrm{~cd}$ & $52,7 \pm 4,7 \mathrm{~cd}$ \\
\hline $\begin{array}{l}14 \text { - Culturas anuais/pastoreio } \\
\text { (mecanizados) }\end{array}$ & $\begin{array}{l}\text { Convexo/terraço fluvial } \\
\text { (8 a 15\%) }\end{array}$ & $1,29 \pm 0,06 \mathrm{~cd}$ & $51,2 \pm 2,1 \mathrm{~cd}$ \\
\hline $\begin{array}{l}15-\text { Culturas anuais/pastoreio } \\
\text { (mecanizados) }\end{array}$ & $\begin{array}{l}\text { Convexo/terraço fluvial } \\
\text { (8 a 15\%) }\end{array}$ & $1,30 \pm 0,10 \mathrm{~cd}$ & $50,9 \pm 3,9 d$ \\
\hline $\begin{array}{l}16 \text { - Culturas anuais (plantio na } \\
\text { palha/mecanizados) }\end{array}$ & Terraço fluvial (6\%) & $1,32 \pm 0,06 \mathrm{~d}$ & $50,1 \pm 2,2 d$ \\
\hline
\end{tabular}

Notas: ${ }^{1}$ Média de 9 amostras; ${ }^{2}$ Desvio Padrão; ${ }^{3}$ Coluna seguida de mesma letra não difere significativamente pelo Teste de Tukey a a $5 \%$. Dados coletados e trabalhados por THOMAZ, E. L. (2004).

\section{QUADRO 3 - DENSIDADE APARENTE $\left(\mathrm{g} / \mathrm{cm}^{3}\right)$ E POROSIDADE TOTAL (\%) NO TOPO DO SOLO (0-5cm), DE ACORDO COM O USO DA TERRA}

Observou-se que duas áreas de pastagem contíguas tiveram comportamento distinto. A pastagem (uso 9) teve solo com densidade de $1,19 \mathrm{~g} / \mathrm{cm}^{3}$, sendo $8,2 \%$ mais denso que a pastagem (uso 6) com $1,10 \mathrm{~g} / \mathrm{cm}^{3} \mathrm{de}$ densidade aparente. A porosidade na pastagem (uso 6) foi $6,7 \%$ superior à de outro uso. Ressalta-se que ambos os parâmetros apresentaram diferença mínima significante $(p<0,05 \%)$ quando foram analisados separadamente.
No uso 6 a pastagem possuía entre 30 e $60 \mathrm{~cm}$ de altura, recobrindo a superfície do solo em mais $90 \%$, além de ter rugosidade superficial maior. No local do uso 9 , a gramínea era rasteira, o solo era recoberto em torno de $70 \%$ e a rugosidade superficial era menor do que na área anterior. Apesar de estarem no mesmo compartimento geomorfopedológico, o manejo formou duas faixas de pastagem distintas, influenciando nas características superficiais do topo do solo de ambas as áreas. 


\section{USO DA TERRA E INFILTRAÇÃO DE ÁGUA NO SOLO}

Empregou-se a técnica de infiltrometria com carga constante durante 1 hora para verificar a capacidade de infiltração de água em diferentes sistemas de uso da terra (THOMAZ; HOMIAK, 2002). Na figura $5 a$, estão representados o comportamento da infiltração nos usos de capoeira, pastagem com diversas características, pastagem degradada (área erodida) e agricultura mecanizada com diversas características. Na figura $5 b$, foi excluído o ensaio realizado em capoeira para melhor representar a infiltração dos outros usos.

De maneira nítida, o uso da terra com capoeira

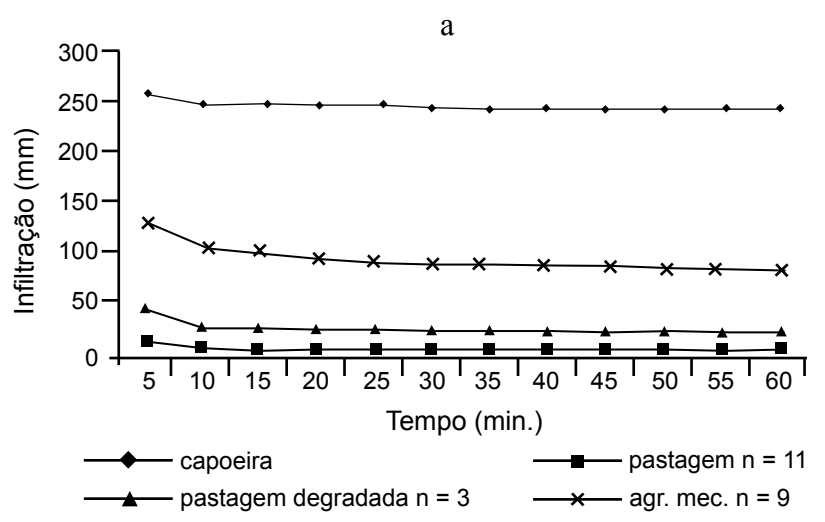

teve a maior infiltração (3 repetições), $2785,4 \mathrm{~mm} / \mathrm{h}$ $(46,4 \mathrm{~mm} / \mathrm{min}$.). Nos primeiros 5 minutos, ela registrou uma infiltração de $246,8 \mathrm{~mm}$ e no final decaiu para $227,8 \mathrm{~mm}$, isto é, uma redução de apenas $8,2 \%$; praticamente, manteve essa taxa de infiltração do início ao fim do ensaio. Portanto, não chegou a atingir a taxa de infiltração básica. (Figura 5a)

$\mathrm{Na}$ seqüência, a agricultura mecanizada (9 repetições) apresentou a maior taxa de infiltração, com 484,9 mm/h (8,1 mm/min.). No início do ensaio, a infiltração média foi de $90 \mathrm{~mm}$ e no final $25,5 \mathrm{~mm}$, resultando num decréscimo significativo. Nesse ensaio, a infiltração estável apresentou um taxa constante, média de $25,5 \mathrm{~mm}(5,3 \%)$ a cada 5 minutos.

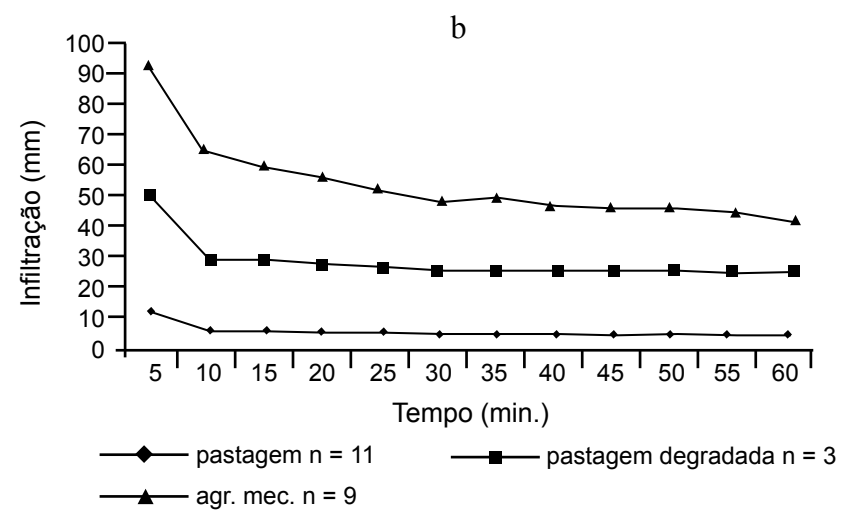

FONTE: Thomaz e Homiak (2002)

\section{FIGURA 5 - A) TAXA INFILTRAÇÃO (Mm) EM CAPOEIRA, PASTAGEM, PASTAGEM DEGRADADA E AGRI- CULTURA MECANIZADA B); TAXA DE INFILTRAÇÃO (Mm) EM PASTAGEM, PASTAGEM DE- GRADADA E AGRICULTURA MECANIZADA}

A pastagem degradada (3 repetições) teve infiltração total de $208,5 \mathrm{~mm} / \mathrm{h}(3,5 \mathrm{~mm} / \mathrm{min}$.). Nos primeiros 5 minutos, registrou infiltração de $46,5 \mathrm{~mm}$ e, no final do ensaio, decaiu para $13,5 \mathrm{~mm}(6,5 \%)$, sendo essa a taxa de infiltração final após uma hora.

A menor infiltração de todos os ensaios foi registrada nas áreas de pastagens (11 repetições), com infiltração total média de $53,6 \mathrm{~mm} / \mathrm{h}(0,983 \mathrm{~mm} / \mathrm{min}$.). Inicialmente, a infiltração foi de $15,8 \mathrm{~mm}$ e no final de somente 2,3 mm. Posto de outra forma, nos primeiros 20 minutos de ensaio houve infiltração de 59,9\% (32,12 $\mathrm{mm}$ ) de toda a água. Nota-se que, a partir desse tempo, a infiltração se manteve relativamente constante. Verificou-se convergência dos resultados obtidos na infiltração de água no solo com a resposta de mudanças físicas superficiais do solo apresentadas nas seções anteriores. 


\section{USO DA TERRA E VARIABILIDADE TÊMPORO- ESPACIAL DAS CONDIÇÕES FÍSICAS DO TOPO DO SOLO}

Avaliou-se em dois momentos uma área de agricultura mecanizada (culturas anuais e pastoreio, uso 15) com o objetivo de verificar as características físicas do topo do solo entre 0 e $5 \mathrm{~cm}$. Foram feitas duas avaliações, uma em 24/6/2002, após preparo da terra (gradagem), e outra em 14/11/2003, com a terra em pousio.

Na primeira avaliação, o solo havia sido gradeado (mecanizado) e estava com a parte superficial $(\approx 15 \mathrm{~cm}$ de profundidade) completamente solta. Essas características dificultaram a retirada de amostras indeformadas, entretanto foi estimado um valor médio padrão para a densidade aparente em torno de $1,00 \mathrm{~g} / \mathrm{cm}^{3}$ e porosidade total $61,0 \%$, a resistência do topo do solo foi inferior a $0,25 \mathrm{kgf} / \mathrm{cm}^{2}$. Na segunda avaliação, 17 meses depois, as condições do topo do solo haviam mudado e os parâmetros físicos mensurados foram os seguintes: densidade aparente $1,30 \mathrm{~g} / \mathrm{cm}^{3}$, porosidade total $50,9 \%$ e resistência de 2,94 kgf/ $\mathrm{cm}^{2}$. (uso 15, Quadro 3)

Ao se comparar as duas avaliações, uma em parte estimada e a segunda mensurada, verificaram-se aumento de $30 \%$ na densidade aparente, porosidade total $19,8 \%$ inferior e resistência 11,8 vezes superior em relação à primeira avaliação. Esse resultado permite concluir, em conjunto com outras análises, a variabilidade das condições físicas do solo de uso para uso, bem como a mudança de condições ocorridas dentro da própria unidade de terra com o passar do tempo.

a

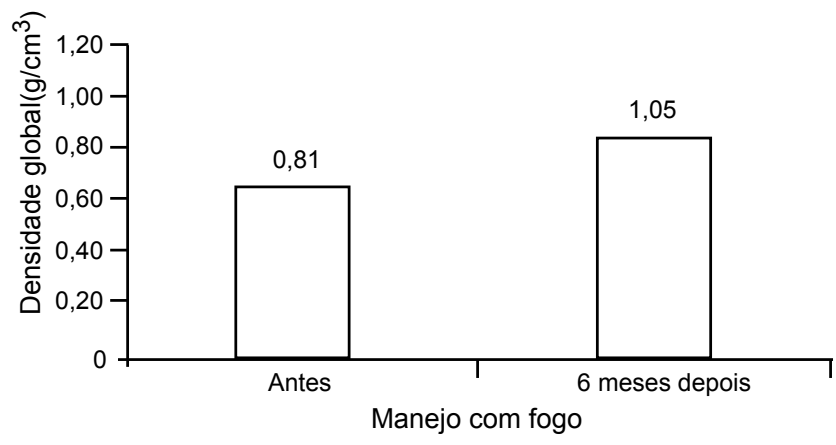

Observou-se ainda mudança superficial do solo em tempo bem mais curto em área que estava em regeneração ( $\approx 8$ anos). Essa área registrou média de serrapilheira recobrindo o solo de $1,28 \pm 0,34 \mathrm{~kg} /$ $\mathrm{m}^{2}$ (uso 2, Tabela 1). Entretanto, durante o monitoramento a área que estava em regeneração por quase uma década foi incorporada ao processo produtivo, seguindo a lógica da rotação de terras descrita em seção anterior.

Dessa forma, verificou-se a modificação no topo do solo $(0-5 \mathrm{~cm})$ causada pela derrubada da capoeira, manejo com fogo e cultivo com milho entre a primavera/ verão $2003 / 2004$. A densidade antes da queimada foi de $0,81 \pm 0,10 \mathrm{~g} / \mathrm{cm}^{3}$ e 6 meses após registrou 1,05 $\pm 0,12$ $\mathrm{g} / \mathrm{cm}^{3}$. Verificou-se que a densidade da segunda avaliação foi $29,6 \%$ superior em comparação à primeira. (Figuras 6a e 6b)

Da mesma maneira, a porosidade total antes do manejo com fogo foi $69,6 \pm 3,7 \%$ e, 6 meses após, $60,5 \pm 4,7 \%$; ocorreu redução de $9,1 \%$ de uma avaliação para outra. Em termos relativos à porosidade total da segunda avaliação, foi $15,0 \%$ inferior ao registrado na primeira. Houve diferença significativa nos dois parâmetros avaliados ( $p<0,05 \%)$.

Em ambos os casos, a primeira coleta continha parte do horizonte $\mathrm{O}_{2}$ (raízes e material orgânico decomposto). Após o fogo, essa camada foi consumida; além disso, observou-se cicatriz de escoamento superficial difuso. Portanto, o fogo e a erosão contribuíram para a mudança nas condições físicas no topo do solo.

Nota: Número de amostra em cada ensaio $(n=11)$.

Dados coletados e trabalhados por THOMAZ, E. L. (2004)

\section{FIGURA 6 - AVALIAÇÃO DA MUDANÇA FÍSICA NO TOPO DO SOLO ANTES E DEPOIS DO MANEJO COM FOGO: A) DENSIDADE APARENTE; B) POROSIDADE TOTAL}


THOMAZ, E. L. Dinâmica do uso da terra e degradação do solo na bacia do Rio Guabiroba - Guarapuava/PR

\section{USO DA TERRA E DEGRADAÇÃO DO SOLO}

Baseando-se nas análises anteriores e a partir de observações em campo, constatou-se que em torno de $80 \%$ ou mais das propriedades, bem como as práticas agropecuárias na bacia do Rio Guabiroba, inserem-se nos níveis de tecnologia nulo e baixo (Quadro 4). As áreas com agricultura de subsistência e pastagens, em áreas com restrições geomorfopedológicas apresentam tecnologia de nível nulo. Apenas as áreas com agricultura mecanizada e pastagens em áreas com menos restrições geomorfopedológicas geralmente restritas ao setor de terraço fluvial, patamares e segmentos de vertentes convexas na transição para o terraço fluvial, são sistemas agrícolas de tecnologia baixa, tendendo em algumas áreas para o nível de tecnologia médio. (THOMAZ, 2005a)

O padrão de uso da terra e o baixo nível tecnológico empregado nas atividades agropecuárias, somados às restrições geomorfopedológicas, assim como às mudanças físicas superficiais no topo dos solos decorrentes dos processos anteriores, condicionam uma dinâmica e, por extensão, uma degradação diferenciada do meio biofísico em cada uso da terra ao longo da bacia, que estão resumidas no Quadro 5.

\begin{tabular}{|lcc|}
\hline NÍVEL TECNOLÓGICO & SÍMBOLO & CARACTERÍSTICAS \\
\hline Tecnologia de nível nulo & $\mathrm{N}$ & $\begin{array}{c}\text { Tecnologia de nível nulo, com adoção de processos, implementos e ferramentas } \\
\text { rudimentares e primitivas. }\end{array}$ \\
Tecnologia de nível baixo & B & $\begin{array}{r}\text { Processos e implementos semitecnificados. Tecnologia ligeiramente desenvolvida } \\
\text { com adoção de técnicas que evidenciam um início de racionalização, } \\
\text { embora ainda em nível baixo ou errôneo. }\end{array}$ \\
Tecnologia de nível médio & M & $\begin{array}{r}\text { Processos e implementos tecnificados. Tecnologia medianamente desenvolvida } \\
\text { e racionalizada. }\end{array}$ \\
Tecnologia de nível elevado & E & $\begin{array}{c}\text { Processos e implementos altamente tecnificados. Tecnologia de nível altamente } \\
\text { avançado e em consonância com as modernas recomendações dos institutos de } \\
\text { experimentação e pesquisas, evidenciando elevado nível de racionalização. }\end{array}$ \\
\hline
\end{tabular}

FONTE: LEPSCH, 1991, p. 105-106.

Organizado por THOMAZ, E. L. (2003).

\section{QUADRO 4 - NÍVEL DE TECNOLOGIA EMPREGADO EM SISTEMAS AGRÍCOLAS}

\begin{tabular}{|c|c|}
\hline USO DA TERRA & INFLUÊNCIA NO MEIO BIOFÍSICO \\
\hline Pastagem & $\begin{array}{l}\text { Nível tecnológico nulo a baixo. Formação de terracetes de pisoteio de gado em área } \\
\text { declivosa; forte erosão laminar e ravinamentos, preferencialmente no caminho uti- } \\
\text { lizado por animais e em carreador interno da propriedade em uso ou abandonado; } \\
\text { mudança física no topo do solo; redução de infiltração, geração de escoamento su- } \\
\text { perficial; reativação (erosão) de canais intermitentes e efêmeros, desbarrancamento } \\
\text { de margens; redução de fontes com fluxo perene; aumento do escoamento nas } \\
\text { estradas. Em algumas áreas, usa-se fogo no manejo, o que causa empobrecimento } \\
\text { do solo e aumento de espécies cespitosas (invasoras). }\end{array}$ \\
\hline Agricultura mecanizada & $\begin{array}{l}\text { Nível tecnológico baixo a médio. Erosão laminar e em sulco; formação de camada } \\
\text { adensada devido ao uso de mecanização, resultando em descontinuidade hidráu- } \\
\text { lica. Elas ocupam boa parte do terraço fluvial, influenciando na redução da mata } \\
\text { ciliar e facilitando o transporte de agroquímicos direto para o sistema fluvial. }\end{array}$ \\
\hline Agricultura de subsistência & $\begin{array}{l}\text { Nível tecnológico nulo. Uso do fogo no manejo da terra; redução da proteção ao } \\
\text { solo; forte erosão laminar; movimentos gravitacionais induzidos por práticas de } \\
\text { manejo ou espontâneos e favorecimento ao estabelecimento de plantas resistentes } \\
\text { ao fogo (espécies cespitosas). }\end{array}$ \\
\hline Florestas secundárias (Faxinal) & $\begin{array}{l}\text { Nível tecnológico nulo. Raleamento interno da floresta (estratos inferiores); redução } \\
\text { do adicionamento de serrapilheira ao solo; mudança na interceptação da chuva; } \\
\text { compactação do solo pelo pisoteio do gado; indução à formação de ravinas no } \\
\text { caminho dos animais; desbarrancamento de margens em canais fluviais; e aumento } \\
\text { da carga sedimentar nos riachos. }\end{array}$ \\
\hline
\end{tabular}

\section{QUADRO 5 - USO DA TERRA DA BACIA DO RIO GUABIROBA E PRINCIPAIS DEGRADAÇÕES DO MEIO BIOFÍSICO}


THOMAZ, E. L. Dinâmica do uso da terra e degradação do solo na bacia do Rio Guabiroba - Guarapuava/PR

\begin{tabular}{|cc|}
\hline USO DA TERRA & INFLUÊNCIA NO MEIO BIOFÍSICO \\
\hline Manchas e corredores degradados & $\begin{array}{c}\text { Áreas com forte erosão laminar e ravinamentos, que induzem ao empobrecimento } \\
\text { físico-químico e biológico do solo; distribui-se de forma irregular pela bacia, espe- } \\
\text { cialmente em áreas de pastagens, agricultura (mecanizada e subsistência), em car- } \\
\text { readores abandonados e locais de extração de cascalho. Alguns setores de canais } \\
\text { fluviais podem ser enquadrados nesta categoria. As áreas degradadas são fontes } \\
\text { de geração de escoamento e de sedimento. Algumas áreas chegam a produzir em } \\
\text { média até } 25,42 \mathrm{~kg} / \mathrm{m} 2 \text { de solo por ano. (THOMAZ; LUIZ, 2004) }\end{array}$ \\
$\begin{array}{c}\text { Áreas densamente recobertas por vegetação; alta proteção ao solo; espessa } \\
\text { Capoeiras em regeneração, florestas secundárias } \\
\text { e florestas com araucária }\end{array}$ & $\begin{array}{c}\text { cobertura de serrapilheira sobre o solo; erosão laminar leve a ausente (escoamento } \\
\text { difuso). Em áreas declivosas >30\%, ocorrem movimentos espontâneos de material } \\
\text { grosseiro; favorecem o fluxo perene e intermitente de fontes de água; proteção aos } \\
\text { corpos hídricos e manutenção da fauna. }\end{array}$ \\
\hline
\end{tabular}

\section{QUADRO 5 - USO DA TERRA DA BACIA DO RIO GUABIROBA E PRINCIPAIS DEGRADAÇÕES DO MEIO BIOFÍSICO}

Outro aspecto a se destacar em relação ao uso da terra e degradação do meio biofísico diz respeito às estradas, aos carreadores e aos caminhos no âmbito da bacia de drenagem. As estradas influenciam na densidade de drenagem da bacia quando se compara a drenagem natural e a rede de circulação viária.

A rede de drenagem na bacia somou $75,38 \mathrm{~km}$ (Dd 3,18 km/km²) (THOMAZ, 2005a). A rede viária registrou 46,68 km, resultando numa densidade de 1,97 $\mathrm{km} / \mathrm{km}^{2}$. Assim, ao se somar a rede drenagem com a rede viária, a extensão atinge $122,06 \mathrm{~km}$, aumentando a densidade para $5,15 \mathrm{~km} / \mathrm{km}^{2}$. O acréscimo da densidade total com a inclusão das estradas foi $38 \%$ superior quando se considerou apenas a drenagem natural.

Estimou-se que a área ocupada pelas estradas e caminhos é de aproximadamente 21 ha, considerando uma largura média de 4,5 m. Segundo Thomaz (2000; 2003), o leito das estradas possui maior coeficiente de escoamento (acima de $50 \%$ ) do que os demais usos como capoeira, floresta, agricultura e pastagem. Além disso, as estradas no geral, e em particular as de circulação interna das propriedades, não possuem disciplinamento do escoamento superficial (dissipação de energia). Disso resulta grande produção de sedimento, haja vista que alguns carreadores se transformam em ravinas. A rede viária, por analogia, pode ser considerada uma rede de drenagem efêmera, pois apresenta rápida resposta hidrológica, isto é, geração significativa de escoamento superficial com posterior diminuição do fluxo após o término do evento pluviométrico.

As estradas, os carreadores e os caminhos cortam grande número de rios e fontes em diferentes unidades de terra. A drenagem lateral nas vias de circulação principal (processo de retirada de água do leito das estradas) faz com que as águas cheguem rapidamente à rede de drenagem, aumentando a vazão. Além disso, esse procedimento compromete a hidrologia das zonas ripárias, já que elas perdem juntamente com a vegetação ciliar a função de filtro, bem como a de regulador da circulação da água entre a transição do sistema fluvial e das vertentes adjacentes. Toda essa dinâmica apresentada deve alterar também o fluxo de sedimento e o ciclo de nutrientes do ecossistema fluvial.

\section{CONSIDERAÇÕES FINAIS}

De maneira geral, o uso da terra coloca o relevo (meio físico) como elemento de suporte e de interface. Entretanto, ele é permeado por uma estrutura agrária que envolve aspectos socioeconômicos, tradições culturais e nível tecnológico (técnicas) empregado no uso das terras agrícolas; tudo isso confere uma dinâmica complexa às unidades de terras da bacia do rio Guabiroba, como foi apresentado.

A ocupação agropecuária é o principal agente dinamizador da paisagem. Dessa forma, as práticas agrícolas nas diferentes unidades de relevo, materializada no uso da terra, impõem uma resposta diferenciada na dinâmica da bacia. A atividade agrícola (calendário agrícola) configurou-se como importante elemento dentro do sistema geomorfológico (baciavertente), individualizando e aprofundando a dinâmica de cada unidade de terra em relação à cobertura do solo, mudanças físicas no topo do solo e infiltração de água e outros. Por decorrência, ocorreu ampla variabilidade têmporo-espacial nos usos e na degradação das terras agrícolas (dinâmica biofísica).

De modo geral, as áreas com pastagens apresentaram significativas mudanças físico-hídricas no solo, o que predispôs as vertentes ao escoamento 
THOMAZ, E. L. Dinâmica do uso da terra e degradação do solo na bacia do Rio Guabiroba - Guarapuava/PR

superficial e resultou em ravinamentos. Em seguida, as áreas mecanizadas e a agricultura de subsistência também apresentaram significativas mudanças superficiais. Além disso, nesses usos ocorreu ampla variabilidade nas características físicas do solo e nas condições de cobertura do solo durante o monitoramento.

Entretanto, as condições físico-hídricas das vertentes com agricultura de subsistência tenderam ao padrão das áreas com capoeira. Por sua vez, as melhores condições físico-hídricas do solo foram verificadas nas áreas com florestas secundárias e capoeiras em regeneração (rotação de terras). Destaca-se que nessas áreas há expressiva quantidade de serrapilheira depo-

\section{REFERÊNCIAS}

AB'SABER, A. N. Províncias geológicas e domínios morfoclimáticos no Brasil. Geomorfologia, USP - IG, n. 20, p. 1-26, 1970.

BIGARELLA, J. J., BECKER, R. D., SANTO, G. F. Cárstico estrutura e origem das paisagens tropicais e subtropicais: fundamentos geológicos-geográficos, alteração química e física das rochas, relevo e dômico. Florianópolis: EDUFSC, 1994.

CASSOL, E. A. et al. Infiltração de água e perdas de água e solo por erosão influenciadas por diferentes métodos de melhoramento da pastagem nativa gaúcha. Revista Brasileira de Ciência do Solo, Viçosa, v. 23, n. 4, p. 923-931, 1999.

CHANG, M. Y. Sistema faxinal: uma de organização camponesa em desagregação no centro-sul do Paraná. IAPAR, Londrina. v. 22, 1988. (Boletim Técnico)

EMBRAPA. Manual de métodos de análise de solos. Centro Nacional de Pesquisa de Solo. 2. ed. Rio de Janeiro, 1997.

GREGORY, K. J. A natureza da geografia física. São Paulo: Bertrand Brasil, 1992.

LEITE, P. F. As diferentes unidades fitoecológicas da região sul do Brasil: proposta de classificação. Cadernos de Geociências, n. 15 , p. 73-164, 1995.

LEPSCH, I. F. (Org.). Manual para levantamento utilitário do meio físico e classificação de terras no sistema de capacidade de uso. Campinas: SBCS, 1991.

MENDES, W.; CASTRO, A. F. Limitações do uso dos solos do Estado do Paraná por suscetibilidade à erosão. Rio de Janeiro: EMBRAPA-SNLCS, 1984.

PHILLIPS, J. D. Earth surface systems: complexity, order, and a scale. Oxford: Blackell Publishers, 1999.

PRIMAVESI, A. Manejo ecológico do solo: a agricultura em regiões tropicais. São Paulo: Nobel, 1999. sitada sobre o solo, o que aumenta a proteção contra a erosão por salpico.

Por fim, este ensaio empregou mensurações e observações sistemáticas realizadas em campo. As mensurações utilizadas foram simples, entretanto são fundamentais nos estudos geomorfológicos e, sobretudo, nos estudos de ecologia da paisagem e mapeamento da paisagem em áreas agrícolas, pois subsidiam a caracterização das unidades de terras, diminuindo a subjetividade envolvida nas análises empíricas. Esses procedimentos podem ser aplicados em escalas de detalhe, como realizado neste estudo (1:10000), até escala média 1:50000.

REICHARDT, K. A água em sistemas agrícolas. São Paulo: Monole, 1990.

ROSS, J. L. S. O registro cartográfico dos fatos geomórficos e a questão da taxonomia do relevo. Revista do Departamento de Geografia, São Paulo, USP, n. 6, p. 17-30, 1992.

SOTCHAVA, V. Por uma teoria de classificação de geossistemas de vida terrestre. Biogeografia, São Paulo, n. 14, p. 1-24, 1978.

THOMAS, M. F.; SIMPSON, I. A. Landscape sensitivity: principles and applications in northern cool temperate environments. Catena, v. 42, n. 2-4, 2001. Especial Issue.

THOMAZ, E. L. Análise empírica da fragilidade potencial da bacia do Rio Iratim, Guarapuava-PR. São Paulo. 188 f. Dissertação (Mestrado em Ciências, área de Geografia Física) - Faculdade de Filosofia Letras e Ciências Humanas, Universidade de São Paulo, 2000.

Hidroclimatologia aplicada à conservação de solo e água. In: SIMPÓSIO BRASILEIRO DE CLIMATOLOGIA GEOGRÁFICA, 5., 2002, Curitiba. Relação de Trabalhos. Curitiba: UFPR, 2002. p. 1098-105. 1 CD-ROM.

Caracterização hidroclimática da bacia do Rio das Pedras. Convênio Fundo Azul II - Sanepar/Unicentro. Guarapuava: UNICENTRO, 2003, 37 p. Relatório TécnicoCientífico.

(a) Caracterização do meio físico da bacia do Rio Guabiroba: ensaio empírico-cartográfico como fundamento ao estudo de processos. In: SIMPÓSIO BRASILEIRO DE GEOGRAFIA FÍSICA APLICADA, 11., 2005, São Paulo. Relação de Trabalhos. São Paulo: Departamento de Geografia/ FFLCH/USP, 2005. p.1616-1631. 1 CD-ROM.

(b) Processos hidrogeomorfológicos e o uso da terra em ambiente subtropical-Guarapuava-PR. São Paulo, 297 f. Tese (Doutorado em Ciência, área de Geografia Física) - Faculdade de Filosofia Letras e Ciências Humanas, Universidade de São Paulo, 2005. 
THOMAZ, E. L. Dinâmica do uso da terra e degradação do solo na bacia do Rio Guabiroba - Guarapuava/PR

THOMAZ, E. L.; HOMIAK, M. Ensaios de capacidade de infiltração de água em diferentes tipos de usos do solo na bacia do Rio Guabiroba, Guarapuava, PR. UNICENTRO: Guarapuava, 2002. (Relatório de iniciação científica).

THOMAZ, E. L.; ROSS, J. L. S. Avaliação crítica em relação ao uso de penetrômetro de bolso na mensuração da capacidade de suporte de materiais. In: SEMINÁRIO DE PESQUISA EM GEOGRAFIA FÍSICA: PERSPECTIVAS DA PESQUISA EM GEOGRAFIA FíSICA, 1., 2008, São Paulo. Anais... São Paulo: USP, 2003. v. 1, p. 195-200.1 CD-ROM.
THOMAZ, E. L.; VESTENA, L. R. Aspectos climáticos de Guarapuava-PR. Guarapuava: Editora UNICENTRO, 2003.

THOMAZ, E. L.; LUIZ, J. C. Mensuração de remoção do solo entre ravinas por meio de técnica dinâmica e volumétrica. In: SIMPÓSIO NACIONAL DE GEOMORFOLOGIA E I ENCONTRO SUL-AMERICANO DE GEOMORFOLOGIA, 5. 2004, Santa Maria. Relação de trabalhos. Santa Maria: UFSM, 2004, 14 p. 1 CD-ROM.

VIERA, S. Estatística experimental. São Paulo: Atlas, 1999. 